\title{
Cellular immunity to cartilage proteoglycans: relevance to the pathogenesis of ankylosing spondylitis
}

Paresh Jobanputra, Ernest H S Choy, Gabrielle H Kingsley, J Sieper, Alberto A Palacios-Boix, Dick Heinegård, Gabriel S Panayi

\begin{abstract}
Cellular immunity to cartilage proteoglycans may be responsible for sustaining chronic inflammation in ankylosing spondylitis. This hypothesis was examined by measuring peripheral blood and synovial fluid mononuclear cell proliferation in five preparations of human cartilage proteoglycan monomer in vitro. Peripheral blood mononuclear cells from 25 patients and synovial fluid mononuclear cells from five patients were compared with those from normal and disease control subjects matched for age. No significant differences were found between the three groups. This suggests that autoimmune responses to cartilage proteoglycans are unlikely to play a significant part in the pathogenesis of ankylosing spondylitis.
\end{abstract}

(Ann Rheum Dis 1992; 51: 959-962)

Autoimmunity to elements of the cartilage matrix may be responsible for sustaining chronic inflammatory arthritis and has been reported for type II collagen in rheumatoid arthritis (RA). ${ }^{1}$ Cellular immunity to human cartilage proteoglycans, the other major constituent of articular cartilage, is recognised in relapsing polychondritis ${ }^{3}$ and may play a part in RA and ankylosing spondylitis. ${ }^{47}$ Other studies have suggested a specific role for cartilage proteoglycans in the pathogenesis of ankylosing spondylitis and $T$ lymphocytes specific for cartilage proteoglycans have been described in the peripheral blood of patients with ankylosing spondylitis. ${ }^{8}$ Ankylosing spondylitis is characterised clinically by extra-articular sites such as the anterior uvea, entheses, and the aortic root being affected. Other proteoglycans immunologically related to cartilage proteoglycans occur at these sites 9 providing further support for the idea that autoimmunity to cartilage proteoglycans is important in ankylosing spondylitis. Arthritis occurs in experimental animals following the injection of cartilage proteoglycans in complete Freund's adjuvant. ${ }^{10}$ This is of particular interest in adjuvant arthritis, a model with some clinical similarities to ankylosing spondylitis. " Relatively few patients with ankylosing spondylitis have been studied and there are no reports of synovial fluid mononuclear cell responses to cartilage proteoglycans. This paper reports in vitro lymphocyte proliferation to cartilage proteoglycans in patients with ankylosing spondylitis, normal controls, and control subjects with arthritis using five different preparations of cartilage proteoglycans.

\section{Patients and methods}

PATIENTS AND CONTROLS

Patients were recruited from the rheumatology outpatient clinics of Guy's and Lewisham Hospitals. Twenty five patients with definite ankylosing spondylitis as defined by the modified New York criteria ${ }^{12}$ took part. Paired synovial fluid and peripheral blood samples were available for four patients and three control subjects with rheumatic disease: one with RA, one with psoriatic arthritis, and one with Reiter's syndrome. Peripheral blood samples from seven other control subjects with rheumatic disease were also tested (three subjects with RA, three with psoriatic arthritis, and one with osteoarthritis. Twenty five healthy subjects served as controls, six of whom were known to be HLA-B27 positive. This group was recruited with the help of the tissue typing laboratory (Guy's Hospital) and had been typed for other reasons. The table gives the clinical characteristics of the patients with ankylosing spondylitis at the time of testing.

\section{SEPARATION OF MONONUCLEAR CELLS}

Peripheral blood and synovial fluid were collected under aseptic conditions into sterile universal tubes containing $0.2 \mathrm{ml}$ heparin. Mononuclear cells were isolated by density gradient centrifugation on Ficoll-Metrizoate (Lymphoprep, Nyegaard, Norway). Cells were washed three times in Hanks's balanced salt solution (HBSS) and adjusted to $2 \times 10^{6} \mathrm{cells} / \mathrm{ml}$ in tissue culture medium which consisted of RPMI 1640 (Gibco, UK) supplemented with $10 \%$ heat inactivated fetal calf serum (Serolab, UK), $2 \mathrm{mM}$ glutamine, and penicillin and streptomycin at $200 \mathrm{U} / \mathrm{ml}$.

\section{ANTIGEN PREPARATIONS}

Five preparations of the central protein core of the monomer believed to be the immunologically

Characteristics of the 25 patients with ankylosing spondylitis studied in this work

\begin{tabular}{ll}
\hline Median (range) age (years) & $46(24-64)$ \\
Sex ratio (M/F) & $22 / 3$ \\
Median (range) disease duration (years) & $10(1-44)$ \\
Mean (range) ESR (mm/hour) & $22(3-50)$ \\
Patients with history of & \\
$\quad$ Peripheral arthritis & 11 \\
Iritis & 6 \\
Treatment & 19 \\
$\quad$ NSAIDs onlyt & $5 \ddagger$ \\
\hline
\end{tabular}

*Data from 19 patients; $E S R=$ erythrocyte sedimentation rate. †NSAIDs=non-steroidal anti-inflammatory drugs.

f Two patients were receiving methotrexate, two sulphasalazine, and one corticosteroids by mouth. 
important fraction of cartilage proteoglycans ${ }^{13}$ were prepared as described previously by Heinegård and Sommarin ${ }^{14}$ using $4 M$ guanidine$\mathrm{HCl}$ gradients. Three samples were prepared from knee condyles, one from the patella (all Al Dl fraction, purified in two sequential gradients, first associative then dissociative; lowest fractions), and one from tracheal cartilage (D1 D1 fraction, purified by two sequential dissociative gradients). Preparations were dissolved in HBBS, filter sterilised, and stored in aliquots at $-20^{\circ} \mathrm{C}$. Tuberculin purified protein derivative (PPD) (Central Veterinary Laboratory, Tunbridge Wells, UK) served as a control antigen.

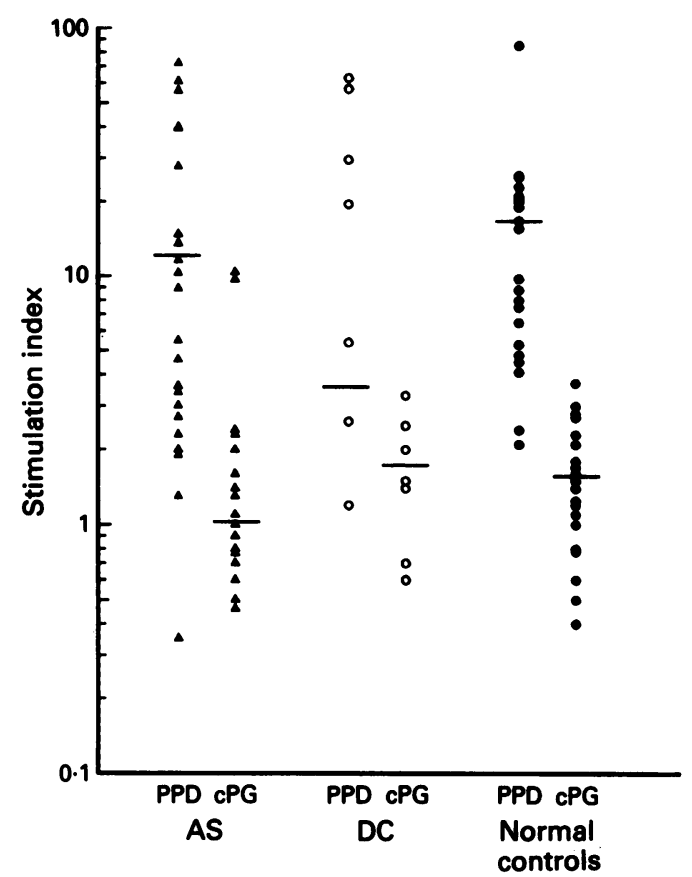

Figure 1 Stimulation indices of peripheral blood mononuclear cells to tuberculin purified protein derivative $(P P D)$ and cartilage proteoglycan (cPG) for the three groups studied. $A S=$ patients with ankylosing spondylitis;

$D C=$ disease controls. Horizontal bars show median values. Note the logarithmic scale; a stimulation index greater than three was considered to be significant.

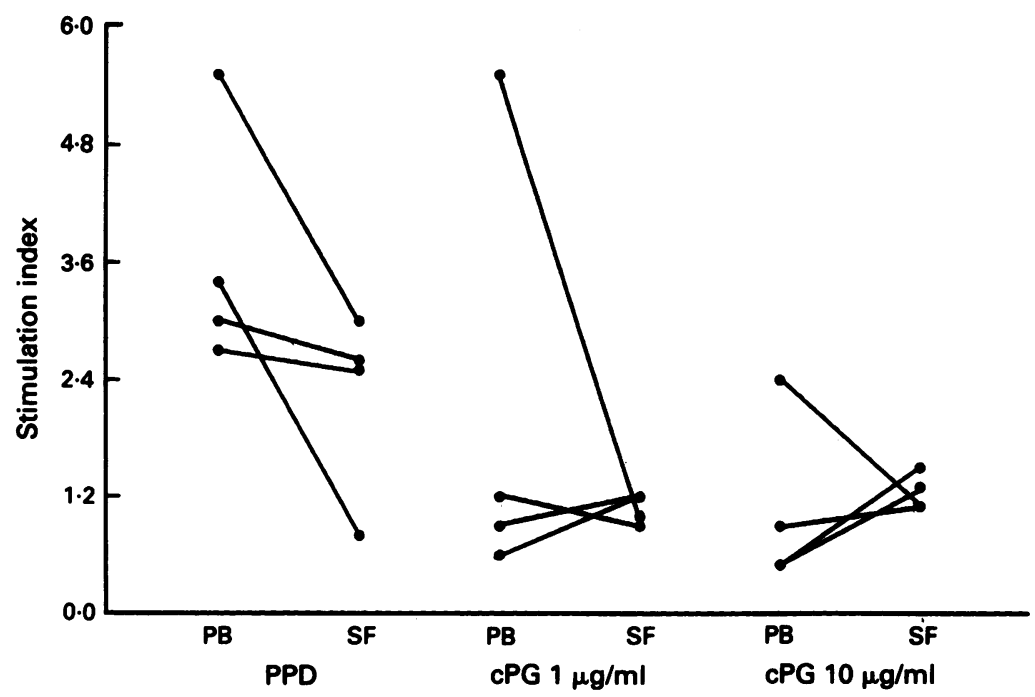

Figure 2 Paired responses of peripheral blood $(P B)$ and synovial fluid $(S F)$ mononuclear cells from patients with ankylosing spondylitis to tuberculin purified protein derivative (PPD) and cartilage proteoglycan (cPG) at two concentrations.
STIMULATION OF MONONUCLEAR CELLS

Mononuclear cells from patients and controls were stimulated with the core protein of cartilage proteoglycans. The concentrations of cartilage proteoglycans tested ranged from 0.2 to 20 $\mu \mathrm{g} / \mathrm{ml}$. Typically $2 \times 10^{5}$ cells/well were cultured in 96 well flat bottomed plates (Nunc, Kamstrup, Denmark). Tuberculin PPD at a concentration of $10 \mu \mathrm{g} / \mathrm{ml}$ established in previous experiments (data not shown) served as a positive control antigen. Cells were cultured in triplicate in a $5 \%$ carbon dioxide incubator for six days with the addition of $7.4 \mathrm{kBq}$ of tritiated thymidine ( ${ }^{3}$ HTdR: Amersham International, Amersham, UK), specific activity $1.9 \times 10^{8} \mathrm{kBq} / \mathrm{mmol}$, for the final 18-20 hours of culture. Cells were harvested on a semiautomated harvester (Skatron, Lier, Norway) and ${ }^{3} \mathrm{HTdR}$ incorporation measured as disintegrations per minute (dpm) by counting in a liquid scintillation counter.

\section{STATISTICAL ANALYSIS}

The results are expressed as stimulation index (SI): the ratio of radioactivity incorporated (dpm) into stimulated cells compared with that incorporated into control cells. Groups were compared by Student's $t$ test.

\section{Results}

There was no significant difference in the ages of patients with ankylosing spondylitis (median age 46 years (range 24-67)), normal control subjects (median $37 \cdot 5$ years (range 24-64)), and control subjects with rheumatic disease (median 41.5 years (range 29-66)). Figure 1 shows the results of antigen stimulation with cartilage proteoglycans and tuberculin PPD in peripheral blood in all three subject groups. There was no statistical difference between the three groups in their SI to tuberculin PPD or cartilage proteoglycans. Significant proliferation occurred when cells were stimulated with tuberculin PPD in contrast to the lack of proliferation to cartilage proteoglycans for all three groups.

The peripheral blood mononuclear cells of three patients showed significant responses to cartilage proteoglycans (SI $5 \cdot 5,9 \cdot 7,10 \cdot 4$ ). Two of these patients had peripheral arthritis and these two had active disease at the time of testing. Synovial fluid was available from one of these patients but synovial fluid mononuclear cells from this patient did not proliferate in response to cartilage proteoglycans. In addition repeated testing of peripheral blood mononuclear cells in these subjects did not show a consistently increased SI (data not shown). One patient with RA from the disease control group responded to cartilage proteoglycans (SI $3 \cdot 3$ ) and two of the normal control subjects also responded to cartilage proteoglycans (SI $3 \cdot 0$, 3.7), one of whom was HLA-B27 positive.

Figure 2 shows the proliferation response of paired peripheral blood and synovial fluid mononuclear cells to cartilage proteoglycans and tuberculin PPD. The proliferative responses of synovial fluid mononuclear cells to tuberculin PPD were reduced compared with the response 
of the corresponding peripheral blood mononuclear cells. There was no evidence of an enhanced response to cartilage proteoglycans with synovial fluid mononuclear cells. Four further extracts of cartilage proteoglycans were used as antigens in proliferation assays with peripheral blood mononuclear cells from five patients and synovial fluid mononuclear cells from one patient. Concentrations of $1-20 \mu \mathrm{g} / \mathrm{ml}$ were tested. No significant stimulation occurred with any preparation of cartilage proteoglycans in the presence of significant stimulation to tuberculin PPD (data not shown).

\section{Discussion}

Proteoglycans are released from cartilage early in the development of experimental models of arthritis $^{15}$ and in patients with acute forms of arthritis such as reactive arthritis. ${ }^{16}$ The antigenic central protein core of these molecules is unlikely to have been encountered by T lymphocytes during their development and this may result in autoimmunity to cartilage proteoglycans leading to prolonged synovitis. Cross reactivity between microbial antigens and self antigens such as cartilage proteoglycans ${ }^{17}$ may account for autoimmune responses to cartilage. It has also been suggested that as free fragments of cartilage proteoglycans within a joint are cationic and have a high molecular weight they may produce synovial changes and their persistence may lead to joint destruction independently of immune responses. ${ }^{18}$ Cartilage proteoglycans, however, although they are released in high concentrations in acute joint inflammation and in trauma, are found in lower concentrations in chronic joint disease and are not disease specific. Investigations of cell mediated immunity to cartilage proteoglycans in inflammatory arthritis have shown a variety of responses, ${ }^{47}$ though some experimental evidence has shown $T$ lymphocytes specific for cartilage proteoglycans in patients with ankylosing spondylitis, ${ }^{8}$ implicating such cells in the pathogenesis of ankylosing spondylitis. Our results with five preparations did not show any specific response to cartilage proteoglycans in patients with ankylosing spondylitis; in the patients showing a response this was not reproducible on repeated testing.

Proteoglycans are complex polydisperse macromolecules with a central protein core which binds a large number of negatively charged carbohydrate side chains. Cartilage proteoglycans vary with the anatomical origin and depth of cartilage and the age of the subject from whom they were extracted. ${ }^{19} 20$ The core protein of larger cartilage proteoglycans (molecular weight 210000 ) shares many antigenic sites and peptide similarities, however, though greater variation has been shown for smaller proteoglycans. ${ }^{9}$ Monomers of cartilage proteoglycans from different sources were used as an antigen in this study and were purified and stored under similar conditions to those used by other workers. Some studies appear to have used pooled sources of cartilage proteoglycans as antigens. ${ }^{5}$ Concentrations of cartilage proteoglycans used in studies reporting a response to cartilage proteoglycans were higher than in our study ${ }^{4}$-typically $30-50 \mu \mathrm{g} / \mathrm{ml}$ compared with our range of $0 \cdot 1-20 \mu \mathrm{g} / \mathrm{ml}$, though in view of the heterogeneity of cartilage proteoglycans direct comparisons may not be valid. This heterogeneity of cartilage proteoglycans may provide an explanation for the variety of responses described in inflammatory arthritis. These factors and the ubiquitous release of cartilage proteoglycans in joint diseases makes it difficult to envisage a role for cartilage proteoglycans as autoantigens. In addition studies implicating cartilage proteoglycans in the pathogenesis of ankylosing spondylitis do not account for the genetic basis of this disease. There appear to be no other methodological differences in the cell proliferation assays performed here compared with those of other studies. Earlier studies have measured the production of leucocyte inhibitory factor as indicative of antigen responses. It has been suggested that these methods may measure different aspects of cellular immunity and may be more sensitive. ${ }^{6}$

In summary we have tested a large number of patients with ankylosing spondylitis for evidence of cellular immunity to purified monomers of cartilage proteoglycans using a range of preparations and have compared the responses with healthy control subjects matched for age. There was no evidence of a specific response in patients with ankylosing spondylitis. Variations in preparations of cartilage proteoglycans may account for the differing responses described in previous studies due to the heterogeneity of human cartilage proteoglycans.

This study was supported by a core support grant (U9) from the Arthritis and Rheumatism Council (ARC) of Great Britain. PJ was supported by an ARC Junior Research Fellowship during this study. We thank our colleagues in the rheumatology unit for their help in obtaining clinical samples.

1 Trentham D E, Dynesius R A, Rocklin R E, David J R. Cellular sensitivity to collagen in rheumatoid arthritis. N Engl f Med 1978; 229: 327-32.

2 Andriopoulos N A, Mestecky J, Miller E J, Bradley E L. Antibodies to native and denatured collagens in sera of patients with rheumatoid arthritis. Arthritis Rheum 1976; 19: 613-7.

3 Rajapakse D A, Bywaters E G L. Cell-mediated immunity to cartilage proteoglycan in relapsing polychondritis. Clin Exp Immunol 1974; 16: 497-502.

4 Golds E E, Stephen I B M, Esdaile J M, Strawczynski H, Poole A R. Lymphocyte transformation to connective tissue antigens in adult and juvenile rheumatoid arthritis, osteoarthritis, ankylosing spondylitis, systemic lupus erythematosus, and a nonarthritic control population. Cell Immunol 1983; 82: 196-209.

5 Glant T, Csongor J, Szucs T. Immunopathologic role of proteoglycan antigens in theumatoid joint disease. Scand $\mathcal{J}$ Immunol 1980; 11 : 247-52.

6 Sigal L H, Johnston S L, Phillips P E. Cellular immune responses to cartilage components in rheumatoid arthritis and osteoarthritis: a review and report of a study. Clin Exp Rheumatol 1988; 6: 59-66.

7 Ofosu-Appiah W A, Warrington R J, Wilkins J A. Interleukin 2 responsive $T$ cell clones from rheumatoid and normal subjects: proliferative responses to connective tissue elements. Clin Immunol Immunopathol 1989; 50: 264-71.

8 Mikec\% K, Glant T T, Baron M, Poole A R. Isolation of proteoglycan-specific $T$ lymphocytes from patients with proteoglycan-specific T lymphocytes from patients with
ankylosing spondylitis. Cell Immunol 1988; 112: 55-63.

9 Heinegärd D, Biörne-Persson A, Cöster L, et al. The core proteins of large and small interstitial proteoglycans from various connective tissues form distinct subgroups. Biochem f 1985; 230: 181-94.

10 Van Vollenhoven R F, Soriano A, McCarthy P E, et al. The role of immunity to cartilage proteoglycan in adjuvan arthritis: intravenous injection of bovine proteoglycan arthritis. intravenous injection of bovine proteoglycan

11 Pearson $C$ M, Wood F D. Studies of polyarthritis and other lesions induced in rats by injection of mycobacterial adjuvant. I. General clinical and pathologic characteristics 
and some modifying factors. Arthritis Rheum 1959; 2: $440-59$.

12 Van der Linden S, Valkenburg H A, Cats A. Evaluation of diagnostic criteria for ankylosing spondylitis: a proposal for madication of the New York criteria. A rthritis R heum 1984; 27: 361-8.

13 Wieslander J, Heinegård D. Immunochemical analysis of cartilage proteoglycans: antigenic determinants of sub structures. Biochem $\mathcal{F}$ 1978; 179: 35-45.

14 Heinegård D, Sommarin Y. Isolation and characterisation of proteoglycans. In: Cunningham L W, ed. Methods in enzymology, structural and contractile proteins, part D, extraenzymology, structural and contractile prote
cellular matrix. Vol 144. 1987: 319-72.

15 Henderson B, Pettipher E R, Murphy G. Metalloproteinases and cartilage proteoglycan depletion in chronic arthritis: comparison of antigen-induced and polycation-induced arthritis. Arthritis Rheum 1990; 33: 241-6.

16 Saxne T, Heinegård D, Wollheim F A. Cartilage proteoglycans in synovial fluid and serum in patients with inflammatory joint disease: relation to systemic treatment. Arthritis Rheum 1987; 30: 972-9.

17 Van Eden W, Holoshitz J, Nevo Z, Frenkel A, Klajman A Cohen I R. Arthritis induced by a T-lymphocyte clone that responds to Mycobacterium tuberculosis and to cartilag proteoglycans. Proc Natl Acad Sci 1985; 82: 5117-20.

18 Boniface R J, Cain P R, Evans C H. Articular responses to purified cartilage proteoglycans. Arthritis Rheum 1988; 31 . purified

19 Roughley P J, White R J. Age-related changes in the structure of proteoglycan subunits from human articular cartilage. F Biol Chem 1980; 255: 217-24.

20 Kuijer $\mathbf{R}$, van de Stadt $\mathbf{R}$ J, van Kampen G P J, de Koning M H M T, van de Voorde-Vissers E, van der Korst J $K$. Heterogeneity of proteoglycans extracted before and after collagenase treatment of human articular cartilage: II. Variations in composition with age and tissue source. Arthritis Rheum 1986; 29: 1248-55. 